\title{
Cross Coupling of Non-Activated Alkyl Halides by a Nickel Pincer Complex
}

\author{
Xile $\mathrm{Hu}^{*}$
}

\begin{abstract}
Non-activated alkyl halides are challenging substrates for cross-coupling reactions because they are reluctant to undergo oxidative addition and because metal alkyl intermediates are prone to $\beta$-H elimination. Despite recent progress, well-defined catalysts are rare. We recently prepared $\mathrm{Ni}$ complexes with a chelating pincer-type bis(amino)amide ligand. The chloride complex $\left[\left({ }^{\mathrm{MeNN}}{ }_{2}\right) \mathrm{NiCl}\right]$ is an active (pre)catalyst for the coupling of non-activated alkyl halides with alkyl, aryl, and heteroaryl Grignard reagents. The catalysis tolerates a wide range of functional groups such as keto, ester, amide, acetal, indole, furan, nitrile, etc. The Ni complex also catalyzes direct alkylation of alkynes and aromatic heterocycles.
\end{abstract}

Keywords: Alkyl halides · Cross coupling · C-H Functionalization · Grignard reagents · Nickel

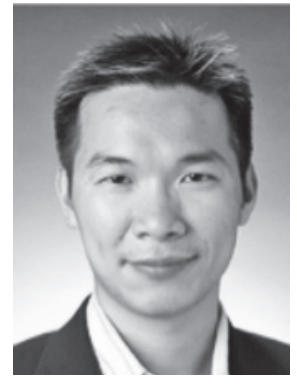

Xile $\mathrm{Hu}$ was born in 1978 in Fujian, China. He studied chemistry at Peking University and received his B.Sc. degree in 2000. Shortly after, he moved to the U.S. and began his doctoral studies under the guidance of Prof. Karsten Meyer at the University of California, San Diego. In December 2004, after having defended his dissertation 'Metal Complexes of Tripodal N-Heterocyclic Carbene Ligands: Synthesis, Structure, Bonding, and Reactivity', he was awarded a Ph.D. in inorganic chemistry. He became a postdoctoral scholar in the group of Prof. Jonas C. Peters at the California Institute of Technology in February 2005. At Caltech, he worked on electrocatalytic hydrogen production. In 2007, he was appointed as a tenure-track assistant professor of chemistry at the École Polytechnique Fédérale de Lausanne (EPFL) in Switzerland, where he directs the Laboratory of Inorganic Synthesis and Catalysis. He is interested in developing catalysts based on earth-abundant elements for applications in synthesis and in energy and sustainability.

${ }^{\star}$ Correspondence: Prof. Dr. X. L. Hu

Ecole Polytechnique Fédérale de Lausanne Institute of Chemical Sciences and Engineering

EPFL-ISIC-LSCI

$\mathrm{CH}-1015$ Lausanne

Tel.: +41216939781

Fax: + 41216939305

E-mail: xile.hu@epfl.ch

\section{Introduction}

$\mathrm{C}-\mathrm{C}$ cross coupling has become one of the standard methods for the construction of new organic molecules. ${ }^{[1]}$ However, not all coupling reactions are developed to the same extent. Whereas coupling of aryl, alkenyl, and alkynyl halides and pseudohalides is readily achieved using $\mathrm{Pd}$ and $\mathrm{Ni}$ catalysis, coupling of non-activated alkyl halides has been challenging. ${ }^{[2-4]}$ The two most often cited causes are: i) alkyl halides are more electron-rich compared to $\mathrm{sp}^{2}$ and sp-hybridized carbon electrophiles and have less tendency to undergo oxidative addition with a metal catalyst; ii) if oxidative addition occurs, the resulting metal alkyl intermediate is prone to unproductive $\beta-\mathrm{H}$ elimination to give olefinic compounds.

While Kochi and co-workers reported thermodynamic and kinetic investigations on cross coupling of alkyl halides in the early 1970 s, ${ }^{[5,6]}$ and Suzuki and co-workers developed the first Suzuki-Miyaura coupling of alkyl halides in 1992,[7] general and preparative methods for cross coupling of nonactivated alkyl halides started to emerge only in the late 1990s. ${ }^{[8,9]}$ Significant progress has been made since then. ${ }^{[2-4,10-19]}$ Nevertheless, compared to cross coupling of aryl and vinyl halides, coupling of non-activated alkyl halides remains under-developed.

Our lab has initiated a research program to develop well-defined coordination complexes of late first-row transition metal ions as catalysts for fine chemical synthesis. Currently, second- and third-row late metals such as Ru, Ir, Rh, Pd, Pt, etc., play essential roles in homogeneous catalysis, especially when a high functional group tolerance is desired. However, these metals are among the rarest on earth and are also expensive. Therefore, there is an impetus to develop efficient catalysts that are based on more

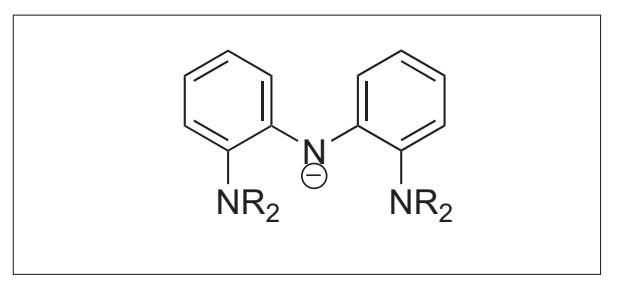

Fig. 1. Pincer $\mathrm{NN}_{2}$ ligand.

abundant and economical metals such as $\mathrm{Fe}, \mathrm{Co}, \mathrm{Ni}, \mathrm{Cu}$, etc.

To match the ionic character of firstrow metals, we designed a pincer-type bis(amino)amide ligand $\mathrm{NN}_{2}$ (Fig. 1). The nitrogen donors have a 'hard' character and should stabilize 'hard' first-row metal fragments. The rigid 'pincer' geometry should contribute additional stability by virtue of the chelate effect. Whereas the chemistry of pincer ligands is ubiquitous, ${ }^{[20]}$ catalytic applications of pincer amine ligands are less exploited.[21]

We find that the Ni-chloride complex of this pincer ligand is an efficient (pre) catalyst for cross coupling of non-activated alkyl halides. The catalysis displays a broad scope and functional group tolerance. These results are summarized in this brief account.

\section{Ligand Synthesis and Coordination Chemistry}

The first ligand we worked on is the dimethyl derivative, ${ }^{\mathrm{Me}} \mathrm{NN}_{2}$. The pro-ligand $\left(\mathrm{H}^{\mathrm{Me}} \mathrm{NN}_{2}\right)$ can be synthesized by a Buchwald-Hartwig coupling[22,23] of $\mathrm{N}, \mathrm{N}$ dimetylaminoaniline and $o-N, N$-dimetylaminobromobenzene, which are readily prepared from commercially available starting materials. ${ }^{[24]}$ Reaction of $\mathrm{H}^{\mathrm{Me}} \mathrm{NN}_{2}$ with ${ }^{\mathrm{n}} \mathrm{BuLi}$ produced a dimeric lithium complex $\left[\left({ }^{\mathrm{Me}} \mathrm{NN}_{2}\right) \mathrm{Li}\right]_{2}$, which proved to be a useful 


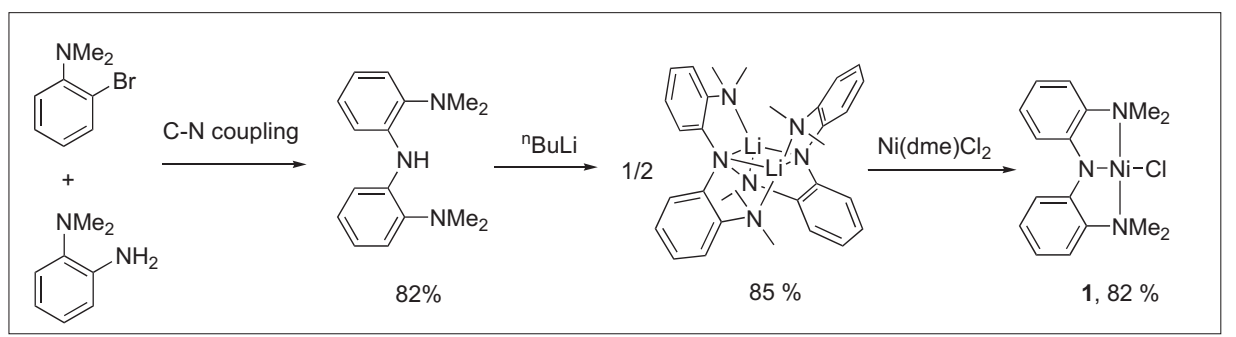

Scheme 1. Synthesis of pro-ligand $\mathrm{H}^{\mathrm{Me}} \mathrm{NN}_{2}$ and its $\mathrm{Ni}$ complex 1 .

ligand transfer reagent to a number of transition metal ions. For example, treatment of $\left[\left({ }^{\mathrm{Me} N N_{2}}\right) \mathrm{Li}\right]_{2}$ with a soluble $\mathrm{Ni}^{\mathrm{II}}$ salt, $\mathrm{NiCl}_{2}(\mathrm{dme})($ dme = dimethoxyethane $)$, afforded the $\mathrm{Ni}$ complex $\left[\left({ }^{\mathrm{Me}} \mathrm{NN}_{2}\right) \mathrm{NiCl}\right](\mathbf{1})$ in a $82 \%$ yield (Scheme 1$)$.

Complex $\mathbf{1}$ is a square-planar Ni complex with the pincer ligand coordinating in the expected meridional fashion. The chloride anion occupies the fourth position. It can be exchanged by another anion or neutral donor through salt metathesis or transmetallation. Thus a large number of four-coordinate $\mathrm{Ni}^{\mathrm{II}}$ pincer complexes were prepared and characterized. ${ }^{[24,25]}$ Noteworthy is the $\mathrm{Ni}^{\mathrm{II}}$ ethyl complex $\left[\left({ }^{\mathrm{Me}} \mathrm{NN}_{2}\right) \mathrm{Ni}\right.$-Et] $(3)$, which resists $\beta$-H elimination even when heated at $80{ }^{\circ} \mathrm{C}$ under $\mathrm{N}_{2}$ (Scheme 2). The latter property is unusual for $\mathrm{Ni}$ and $\mathrm{Pd}$ alkyl complexes, and gives a first indication that this $\left(\mathrm{NN}_{2}\right) \mathrm{Ni}$ platform might support efficient transformation of non-activated alkyl groups.

\section{Cross Coupling of $\mathrm{CH}_{2} \mathrm{Cl}_{2}$ with Grignard Reagents}

While studying the reactivity of $\left(\mathrm{NN}_{2}\right) \mathrm{Ni}$ alkyl species, we made a serendipitous dis- covery. We found that the methyl complex $\left(\left[\left({ }^{\mathrm{Me} N N_{2}}\right) \mathrm{Ni}-\mathrm{Me}\right], 2\right)$ reacted with $\mathrm{CH}_{2} \mathrm{Cl}_{2}$ and $\mathrm{CHCl}_{3}$ to give the chloride complex 1 in nearly quantitative yields. ${ }^{[24]}$ Surprisingly, the only identifiable organic products were n-propane and isobutane, respectively (Scheme 3). Thus during these reactions, multiple alkylation occurred at the same carbon center. As no partially alkylated products could be found, initially we suspected that the reactions proceeded through consecutive alkylations and the rates of 2 nd and 3rd alkylation steps were faster than their proceeding steps. However, control experiments showed that $\mathrm{CH}_{2} \mathrm{Cl}_{2}$ reacted with 1 slightly faster than $\mathrm{CH}_{3} \mathrm{CH}_{2} \mathrm{Cl}$, suggesting that consecutive alkylation did not take place. The exact mechanism is still under investigation. However, we have rendered these stoichiometric reactions catalytic, and have reported the first double alkylation of $\mathrm{CH}_{2} \mathrm{Cl}_{2}$ with Grignard reagents. [24]

As shown in Scheme 4, different primary alkyl Grignard nucleophiles can be coupled. Branching at the $\beta$-position of the Grignard reagent is tolerated. The maximum turnover number is 47 . The reactions are rapid and finish within minutes at $-20^{\circ} \mathrm{C}$. Coupling of $\mathrm{CD}_{2} \mathrm{Cl}_{2}$ is equally efficient. Unfortunately $2\left[\left({ }^{\mathrm{Me}} \mathrm{NN}_{2}\right) \mathrm{Ni}-\mathrm{Me}\right]+\mathrm{CH}_{2} \mathrm{Cl}_{2} \longrightarrow 2\left[\left(\mathrm{Me}_{2} \mathrm{NN}_{2}\right) \mathrm{Ni}-\mathrm{Cl}\right]+\left(\mathrm{CH}_{3}\right)_{2} \mathrm{CH}_{2}$
$3\left[\left({ }^{\mathrm{Me}} \mathrm{NN}_{2}\right) \mathrm{Ni}-\mathrm{Me}\right]+\mathrm{CHCl}_{3} \longrightarrow 3\left[\left({ }^{\mathrm{Me}} \mathrm{NN}_{2}\right) \mathrm{Ni}-\mathrm{Cl}\right]+\left(\mathrm{CH}_{3}\right)_{3} \mathrm{CH}$
Scheme 3. Reactions of complex 2 with $\mathrm{CH}_{2} \mathrm{Cl}_{2}$ and $\mathrm{CHCl}_{3}$.

Scheme 4. Catalytic double alkylation of $\mathrm{CH}_{2} \mathrm{Cl}_{2}$.
TON up to 47

Selected products:

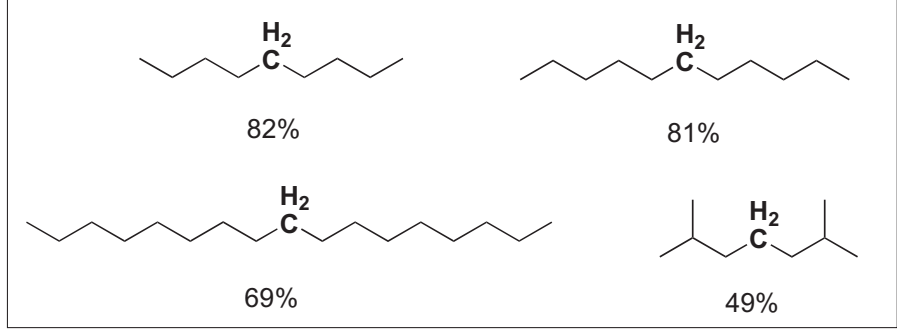

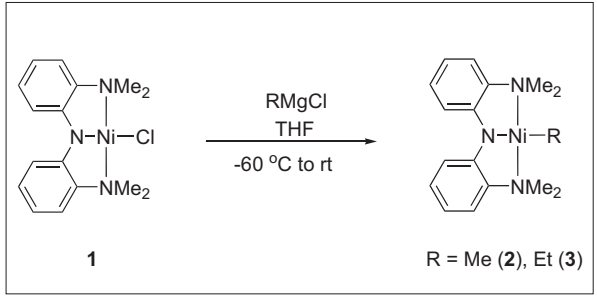

Scheme 2. Synthesis of $\left[\left({ }^{\mathrm{Me}} \mathrm{NN} \mathrm{N}_{2}\right) \mathrm{Ni}\right.$-alkyl] complexes $\mathbf{2}$ and $\mathbf{3}$.

the scope of the catalysis remains limited, as secondary and tertiary alkyl as well as aryl Grignard reagents could not be coupled. Coupling of other di- and tri-chloroalkanes was not successful. ${ }^{[25]}$ Further improvement is needed to make this coupling reaction applicable in synthesis.

\section{Cross Coupling of Alkyl Halides with Alkyl Grignard Reagents}

Even though Ni alkyl complexes 2 and 3 are stable square-planar $\mathrm{Ni}^{\mathrm{II}}$ species, they do react with non-activated alkyl halides including chlorides to form the corresponding $\mathrm{Ni}$ halide complexes and alkyl-alkyl coupled products in high yields (Scheme 5). ${ }^{[24]}$ These reactions form the basis for the cross coupling of non-activated alkyl halides with alkyl Grignard reagents. Indeed, complex $\mathbf{1}$ is a competent (pre)catalyst for this $\mathrm{sp}^{3}-\mathrm{sp}^{3}$ coupling. ${ }^{[25,26]} \mathrm{A}$ loading of 3 $\mathrm{mol} \%$ catalyst is sufficient under most circumstances, and the reactions proceeded smoothly between $-20{ }^{\circ} \mathrm{C}$ to $-35{ }^{\circ} \mathrm{C}$ in dimethylacetamide (DMA). Primary alkyl iodides and bromides as well as secondary alkyl iodides were readily coupled (Scheme $6)$. The mild conditions prompted us to investigate the functional group tolerance of this coupling method. To our delight, ester, amide, keto, ether, thioether, acetal, nitrile, various heterocyclic groups, and even aryl halide units are well tolerated. ${ }^{[26}$ This broad scope is unusual for coupling reactions using alkyl Grignard reagents as nucelophiles, and underscores the high activity of the Ni catalyst for cross coupling.

\section{Cross Coupling of Alkyl Halides with Aryl and Heteroaryl Grignard Reagents}

After the initial success in alkyl-alkyl coupling, we wanted to see if the catalysis can be extended to the coupling of alkyl halides with aryl and heteroaryl Grignard reagents. The resulting aryl and heteroaryl containing products are significant organic molecules as natural products, biologically active small molecules, and materials. Gratifyingly, complex $\mathbf{1}$ is also an efficient (pre) catalyst for this $\mathrm{sp}^{3}-\mathrm{sp}^{2}$ coupling, but under 

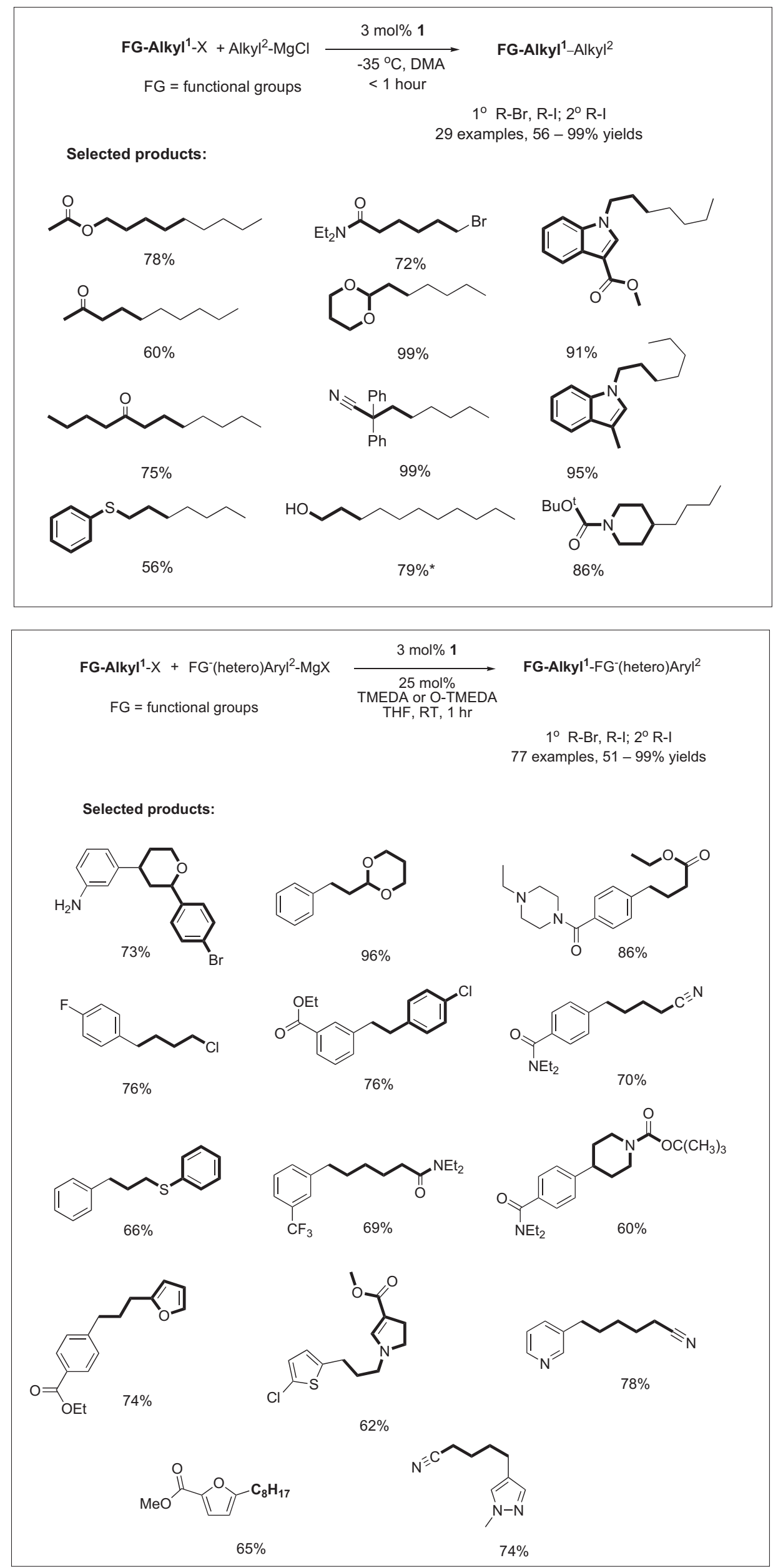

Scheme 7. Catalytic alkyl-(hetero)aryl cross coupling.
Scheme 6. Catalytic alkyl-alkyl cross coupling; * for coupling of this substrate, 2 equiv. of Grignard reagents were used.

modified conditions. ${ }^{[27]}$ The best results were obtained in THF at room temperature, and a catalytic amount ( $c$ a. $25 \mathrm{~mol} \%$ ) of amine additive (TMEDA or O-TMEDA) was beneficial. Again $3 \mathrm{~mol} \%$ of catalyst is sufficient, and primary alkyl iodides and bromides as well as cyclic secondary alkyl iodides could be used (Scheme 7). Both electron-rich and electron-poor nucleophiles worked. The most interesting feature of this coupling method is that it allows the coupling of functionalized aryl and heteroaryl Grignard reagents that were developed by Knochel and coworkers. ${ }^{[28-30]}$ Thus our $\mathrm{Ni}$-catalysis expands significantly the scope of Kumada-Corriu-Tamao coupling, ${ }^{[31,32]}$ making this atom-economic and cost-effective coupling technology attractive for the construction of more complex molecules and materials.

\section{Cross Coupling of Alkyl Halides with Terminal Alkynes}

Metal-catalyzed cross coupling of organic halides with terminal alkynes, or the Sonogashira reaction, is one of the most powerful methods for the preparation of substituted alkynes.[33] Whereas coupling of aryl and vinyl halides can be readily achieved using $\mathrm{Pd} / \mathrm{Cu}$ catalysis, coupling of alkyl halides remains difficult. There were two prior reports on successful Sonogashira coupling of non-activated alkyl halides using Pd N-heterocyclic carbene catalysts. ${ }^{[12,34]}$ The high efficiency of catalyst $\mathbf{1}$ in Kumada-Corriu-Tamao coupling of alkyl halides prompted us to investigate its activity in Sonogashira coupling of the same substrates. After exploring a wide range of conditions, we found that coupling of primary alkyl iodides and terminal alkynes was successful at $100{ }^{\circ} \mathrm{C}$ in dioxane using $5 \mathrm{~mol} \%$ $\mathbf{1}$ as (pre)catalyst, $3 \mathrm{~mol} \% \mathrm{CuI}$ as co-catalyst, and 1.4 equiv. of $\mathrm{Cs}_{2} \mathrm{CO}_{3}$ as base. ${ }^{[35]}$ To couple alkyl bromides, $20 \mathrm{~mol} \%$ of $\mathrm{NaI}$ was needed, presumably to convert alkyl bromides into iodides. To couple alkyl chlorides, $20 \mathrm{~mol} \%$ of $\mathrm{n}-\mathrm{Bu}_{4} \mathrm{NI}$ and a temperature of $140{ }^{\circ} \mathrm{C}$ were needed. The different reactivity of alkyl halides enabled their sequential functionalization.

Despite the relative elevated temperature required for the Ni-catalyzed Sonogashira coupling, a good functional group tolerance was achieved (Scheme 8). ${ }^{[35]}$ Ester, amide, aromatic enone, keto, acetal, nitrile, and heterocycle groups did not interfere with the coupling. Moreover, an array of terminal alkynes with alkyl, aryl, TMS, and OTMS substituents could be coupled. 
Thus, for the preparation of highly functionalized alkynes, this coupling method compares favorably with the alternative synthesis by reaction of alkyl halides with alkynyl anions in cryogenic conditions. ${ }^{[36]}$

\section{Summary and Outlook}

Ni pincer complex 1 shows a remarkable activity in a number of cross-coupling reactions of non-activated alkyl halides. The high efficiency of the catalysis is reflected by its broad substrate scope and high functional group tolerance. The coupling methods described here are applicable to the synthesis of a large number of complex small molecules containing non-activated alkyl groups.

One advantage of using preformed and well-defined complexes such as $\mathbf{1}$ as (pre) catalyst is that it simplifies mechanistic study and considerations. We have started to probe the mechanism of the cross-coupling reactions. For example, using radical-probe substrates, we showed that the activation of alkyl halides likely took place via a radicalrebound mechanism. ${ }^{[25,26]}$ And by studying stoichiometric reactions of analogous $\mathrm{Ni}$ pincer complexes, we proposed a formal $\mathrm{Ni}{ }^{\mathrm{II}} / \mathrm{Ni}^{\mathrm{IV}}$ couple for the Kumada-CorriuTamao coupling reactions. ${ }^{[25,27]}$ Further kinetic and reactivity studies are currently being performed to elucidate the mechanistic details of these catalytic reactions.

In the area of cross coupling of nonactivated alkyl halides, one attractive goal is to avoid the use of stoichiometric organometallic reagents and to couple alkyl halides directly to $\mathrm{C}-\mathrm{H}$ bonds. Our lab has recently begun to explore $\mathrm{C}-\mathrm{H}$ functionalization reactions using alkyl halides as electrophiles. A paper on ' $\mathrm{Ni} / \mathrm{Cu}$-catalyzed direct alkylation of heterocyclic C-H bonds' is in press. ${ }^{[37]}$

\section{Acknowledgements}

I would like to thank my co-workers for their lab-work and intellectual contributions. Their names appear in the relevant group publications cited in this account. I want to specially thank Mr. Oleg Vechorkin for spearheading this project. Our work has been supported by the EPFL and the Swiss National Science Foundation (project no. 126498).

Received: February 15, 2010

[1] 'Metal-Catalyzed Cross-Coupling Reactions', 2nd ed., Eds. A. de Meijere, F. Diederich, Wiley$\mathrm{VCH}$, Weinheim, 2004.

[2] M. R. Netherton, G. C. Fu, Adv. Synth. Catal. 2004, 346, 1525.

[3] A. C. Frisch, M. Beller, Angew. Chem., Int. Ed. 2005, 44, 674.

[4] A. Rudolph, M. Lautens, Angew. Chem., Int. Ed. 2009, 48, 2656

[5] M. Tamura, J. Kochi, J. Am. Chem. Soc. 1971, 93, 1483.

[6] M. Tamura, J. K. Kochi, J. Organomet. Chem. 1972, 42, 205.

[7] T. Ishiyama, S. Abe, N. Miyaura, A. Suzuki, Chem. Lett. 1992, 691.

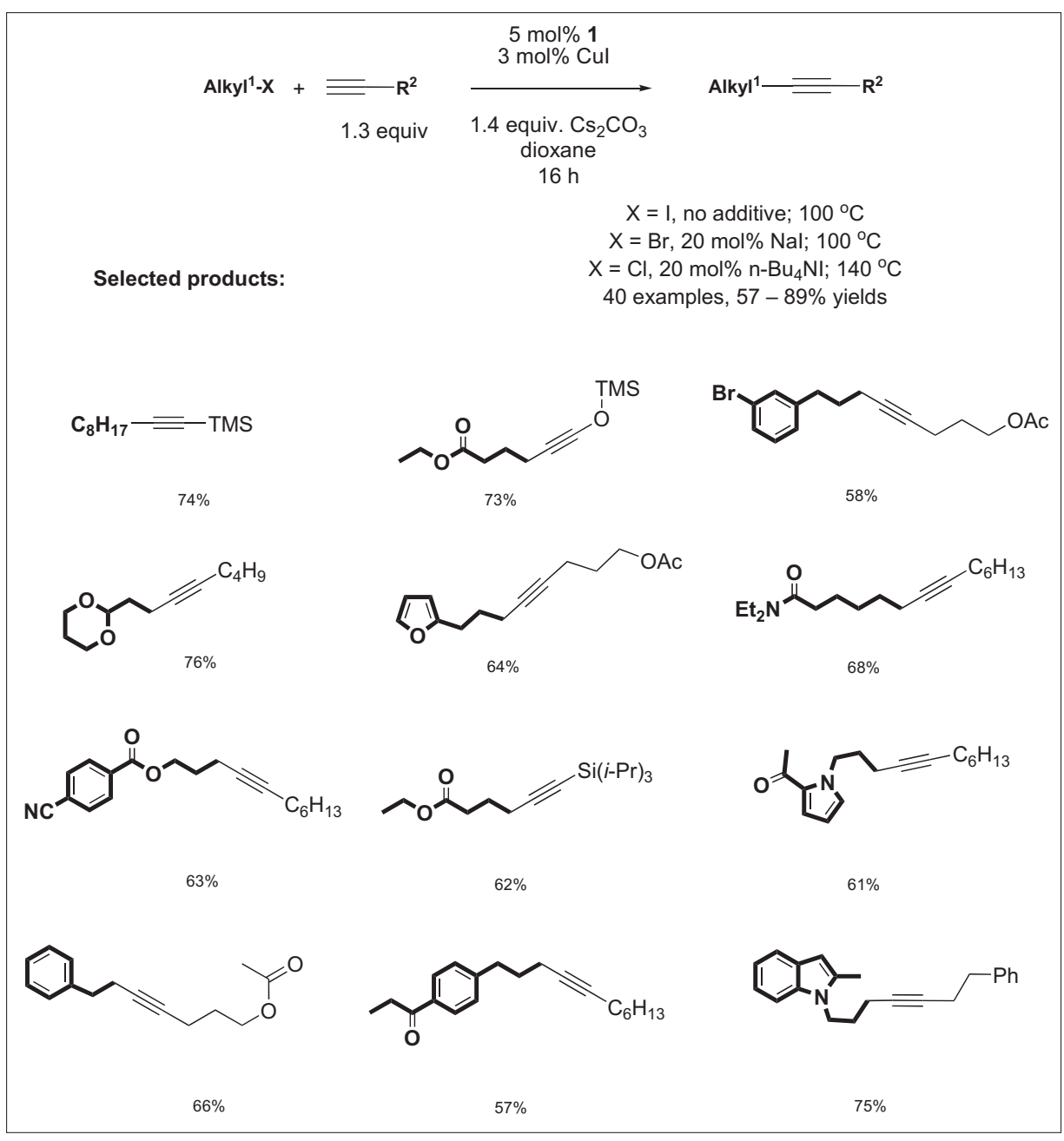

Scheme 8. Catalytic Sonogashira coupling of alkyl halides.

[8] A. Devasagayaraj, T. Studemann, P. Knochel, Angew. Chem., Int. Ed. 1995, 34, 2723.

[9] R. Giovannini, T. Studemann, G. Dussin, P. Knochel, Angew. Chem., Int. Ed. 1998, 37, 2387.

[10] G. Cahiez, C. Chaboche, M. Jezequel, Tetrahedron 2000, 56, 2733.

[11] M. R. Netherton, C. Y. Dai, K. Neuschutz, G. C. Fu, J. Am. Chem. Soc. 2001, 123, 10099.

[12] M. Eckhardt, G. C. Fu, J. Am. Chem. Soc. 2003, $125,13642$.

[13] K. Menzel, G. C. Fu, J. Am. Chem. Soc. 2003 , $125,3718$.

[14] J. R. Zhou, G. C. Fu, J. Am. Chem. Soc. 2003, $125,14726$.

[15] N. A. Strotman, S. Sommer, G. C. Fu, Angew. Chem., Int. Ed. 2007, 46, 3556.

[16] A. C. Frisch, N. Shaikh, A. Zapf, M. Beller, Angew. Chem., Int. Ed. 2002, 41, 4056.

[17] R. Martin, A. Furstner, Angew. Chem., Int. Ed. 2004, 43, 3955.

[18] G. D. Jones, J. L. Martin, C. McFarland, O. R. Allen, R. E. Hall, A. D. Haley, R. J. Brandon, T. Konovalova, P. J. Desrochers, P. Pulay, D. A. Vicic, J. Am. Chem. Soc. 2006, $128,13175$.

[19] J. Terao, N. Kambe, Acc. Chem. Res. 2008, 41, 1545.

[20] 'The Chemistry of Pincer Compounds', Eds. D. Morales-Morales, C. M. Jensen, Elsevier, Amsterdam, 2007.

[21] M. Albrecht, G. van Koten, Angew. Chem., Int Ed. 2001, 40, 3750.

[22] J. P. Wolfe, S. Wagaw, J. F. Marcoux, S. L. Buchwald, Acc. Chem. Res. 1998, 31, 805.

[23] J. F. Hartwig, Acc. Chem. Res. 1998, 31, 852.
[24] Z. Csok, O. Vechorkin, S. B. Harkins, R. Scopelliti, X. L. Hu, J. Am. Chem. Soc. 2008 130,8156 .

[25] O. Vechorkin, Z. Csok, R. Scopelliti, X. L. Hu, Chem.-Eur. J. 2009, 15, 3889.

[26] O. Vechorkin, X. L. Hu, Angew. Chem., Int. Ed. 2009, 48, 2937.

[27] O. Vechorkin, V. Proust, X. L. Hu, J. Am. Chem. Soc. 2009, 131, 9756.

[28] P. Knochel, A. Krasovskiy, I. Sapountzis, in 'Handbook of Functionalized Organometallics', Vol. 1, Ed. P. Knochel, Wiley-VCH, Weinheim, 2005, pp. 109.

[29] P. Knochel, W. Dohle, N. Gommermann, F. F. Kneisel, F. Kopp, T. Korn, I. Sapountzis, V. A. Vu, Angew. Chem., Int. Ed. 2003, 42, 4302.

[30] F. M. Piller, P. Appukkuttan, A. Gavryushin, M. Helm, P. Knochel, Angew. Chem., Int. Ed. 2008, 47, 6802 .

[31] K. Tamao, K. Sumitani, M. Kumada, J. Am. Chem. Soc. 1972, 94, 4374.

[32] R. J. P. Corriu, J. P. Masse, J. Chem. Soc., Chem. Commun. 1972, 144.

[33] K. Sonogashira, in 'Handbook of Organopalladium Chemistry for Organic Synthesis', Ed. E. Negishi, Wiley-Interscience, New York, 2002, pp. 493-529.

[34] G. Altenhoff, S. Wurtz, F. Glorius, Tetrahedron Lett. 2006, 47, 2925.

[35] O. Vechorkin, D. Barmaz, V. Proust, X. L. Hu, J. Am. Chem. Soc. 2009, 131, 12078.

[36] J. N. Shepherd, J. R. Stenzel, J. Chem. Educ. 2006, $83,425$.

[37] O. Vechorkin, V. Proust, X. L. Hu, Angew. Chem., Int. Ed. 2010, in press, DOI: 10.1002/ anie. 200907040. 